Part of Journal of Research of the National Bureau of Standards, Volume 25, July 1940

\title{
DETERMINATION OF THICKNESS OF ACID-RESISTANT PORTION OF VITREOUS ENAMEL COATINGS
}

\author{
By William N. Harrison and Leo Shartsis
}

\begin{abstract}
A method is described whereby an oblique section of the enamel approximately $1 \mathrm{~cm}$ wide is exposed by grinding. The boundaries of this section are permanently marked, and the oblique section is given a fire polish by refiring. The surface is then exposed to acid, after which it is coated with colored wax. Upon rubbing the surface, this wax is removed from the acid-resisting enamel, which retains its gloss in the acid, but is retained by the etched portion of the oblique section. The fraction of the oblique section which is occupied by the acid-resisting enamel is then determined, and this fraction is multiplied by the total thickness of enamel as measured by a magnetic gage. The product gives the thickness of the layer of acid-resisting enamel.
\end{abstract}

\section{CONTENTS}

I. Introduction

II. Method of test _.. 71

III. Accuracy of method

IV. Conclusion

\section{INTRODUCTION}

In the course of revision of the Federal specification for plumbing fixtures, including the incorporation of specifications for formed-metal sanitary ware, the Enameled Metals Section of the National Bureau of Standards was asked to make recommendations. Because the practice in enameling sheet iron by the wet process is to apply first a non-acid-resistant coating over the ground coat and to follow this by an acid-resistant coating (when required), it is not possible by a mere determination of the total thickness of enamel to discover how heavy a coating of acid-resistant enamel has been applied. Since it is desirable to specify a minimum thickness for the acid-resistant layer of enamel, it was necessary to devise a test method for determining this thickness. The present paper describes a method which was found satisfactory.

\section{METHOD OF TEST}

The method of test is based on a principle illustrated by figure 1, which shows in diagrammatic form an oblique section through an enamel coating on iron. The device of cutting an oblique section at a small angle to the enamel surface permits measurements of distances much larger than the comparatively small thickness of acidresistant enamel which may be present. 
By geometry, it can be shown that in a specimen as represented in figure 1 the thickness, $a b^{\prime}$, of the acid-resistant enamel may be computed from measurements of other distances, as follows:

$$
\frac{a b^{\prime}}{a d^{\prime}}=\frac{a b}{a d}, \text { or } a b^{\prime}=a d^{\prime} \times \frac{a b}{a d}
$$

Stated verbally, the thickness of the acid-resistant coating equals the total enamel thickness multiplied by the ratio of the width of the acid-resistant section to the total width of the oblique section of enamel.

Using this principle, the following procedure was adopted for testing commercial articles:

Remove a flat or nearly flat section of the article to be tested, not less than 5 by $5 \mathrm{~cm}$ in size. ${ }^{1}$ (The article may be cut with the flame

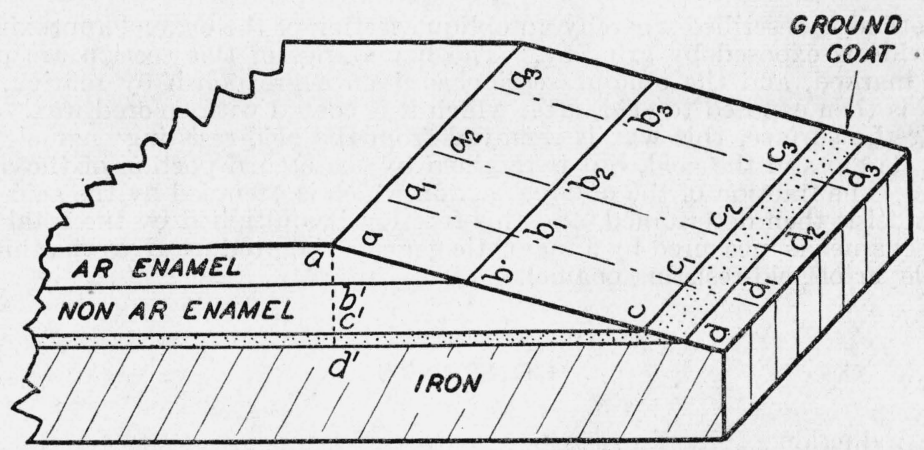

FIGURE 1.-Sketch of specimen showing cross section and oblique section of enamel applied in three coats over iron.

$A R$ means acid-resisting. Lines $a_{1} d_{1}, a_{3} d_{3}$, etc., are explained in the text.

of a suitable torch, or with a hacksaw.) Along one edge of the specimen, other than an edge of the original article, grind off the enamel in a plane at an angle of approximately $5^{\circ}$ to the surface of the enamel, exposing an oblique section of the enamel coating and part of the underlying metal at least $5 \mathrm{~cm}$ in length (see line $d d_{3}$, fig. 1). The width of the exposed oblique section of the enamel, measured along its surface (distances $a_{1} d_{1}$ and $a_{3} d_{3}$ ), shall be 1.0 $\pm 0.25 \mathrm{~cm}$ for sheet-metal articles, or $2.0 \pm 0.5 \mathrm{~cm}$ for dry-process cast-iron articles. The abrasive ${ }^{2}$ used in grinding shall pass a No. 150 sieve and shall be moistened during grinding. The grinding may be done on a brass or glass flat, using a shim under one side of the specimen to obtain the desired $5^{\circ}$ angle. After grinding, mark the boundary between the original glossy surface and the treated surface of the enamel by a very narrow line, made with a ceramic underglaze pencil, ${ }^{3}$ and rub with a dry cloth until any marking on the glossy surface is removed. There will remain the line $a a_{3}$, figure 1 .

With the same marking agent, make three straight lines $\left(a_{1} d_{1}\right.$, $a_{2} d_{2}$, and $\left.a_{3} d_{3}\right)$ as narrow as can be plainly seen, at intervals of $1 \mathrm{~cm}$ or more, across the oblique section of enamel, perpendicular to the

\footnotetext{
1 Obviously, small laboratory specimens may be tested by this method without reducing their size.

2 Silicon carbide was found to be satisfactory for this purpose.

3 For this particular method of marking the boundary the authors are indebted to M. G. Ammon, of the Ferro Enamel Corporation.
} 
boundary, $d d_{3}$, between the enamel and the exposed iron base. None of these lines shall be closer than $1.5 \mathrm{~cm}$ to an edge of the specimen which was an edge of the original article. Along each of these lines, measure the width of the oblique section of enamel between the exposed iron base and the original enamel surface. (The width of the line, $a a_{3}$, made with the ceramic underglaze pencil, must be included in the measured distances.)

Refire the specimen just sufficiently to obtain a fire polish on the oblique section of enamel. After cooling, immerse the treated portion of the specimen in 10-percent citric acid for 15 minutes, at room temperature $\left(80^{\circ} \pm 10^{\circ} \mathrm{F}\right)$. After rinsing and drying the specimen, rub the entire oblique section of enamel with a colored-wax pencil, then rub the deposit of colored wax with a dry cloth. The acidresistant portion of the enamel coating (between lines $a a_{3}$ and $b b_{3}$ ) will have retained its fire polish in the acid solution, and the colored deposit of wax will be readily removed from it but will remain on the etched portion of the cross-section (between lines $b b_{3}$ and $d d_{3}$, fig. 1). The acid-resistant band of enamel in the oblique section will then be bounded on one side by the colored-wax deposit and on the other by the edge of the ceramic-pencil mark, $a a_{3}$, which is adjacent to the original glossy surface of the enamel.

Measure the width of this acid-resistant band at the three pencil marks along which the width of the total oblique section has previously been measured $\left(a_{1} d_{1}, a_{2} d_{2}\right.$, and $\left.a_{3} d_{3}\right)$, and compute the average width ratio of the acid-resistant portion to the total oblique section of enamel (the average of $a_{1} b_{1} / a_{1} d_{1}, a_{2} b_{2} / a_{2} d_{2}$, and $a_{3} b_{3} / a_{3} d_{3}$ ). All measurements on the oblique section shall be made with an accuracy of $\pm 0.1 \mathrm{~mm}$ (0.004 inch), using preferably a transparent millimeter scale. Measure the total enamel thickness adjacent to the location of the measurements described above, using a magnetic thickness gage or other suitable means having an error less than 0.001 in. $(0.025 \mathrm{~mm})$. Multiply the average value for total thickness by the average ratio of acid-resisting enamel to total enamel, determined as described above. The product equals the thickness of the acidresisting portion of the enamel coating.

When this test is used for control purposes by a manufacturer, it may frequently be possible to shorten the procedure considerably, because the line of demarcation, $b b_{3}$, between the acid-resistant and the non-acid-resistant enamel is frequently visible immediately after the grinding of the oblique section. Since all necessary boundaries in such a case are already visible, no marking of boundaries with ceramic underglaze pencil, nor refiring, nor acid treatment, is necessary.

\section{ACCURACY OF METHOD}

A number of determinations were made to check the experimentally determined thicknesses of the acid-resistant portions of enamel coatings against known amounts of the enamel applied to laboratory specimens. Known weights per unit area of acid-resistant enamel were applied over nonresistant enamels, and the thicknesses of the final coatings were determined by the method described in section II. They were also computed from the specific gravity of the enamel.

The coatings of acid-resistant enamel were applied over fired coats, and also over coats which had been sprayed on and dried, but not 
fired. In either case the acid-resisting coating was, of course, fired. Table 1 shows some typical results, which indicate that the estimated and determined thicknesses usually agree within about one-half to three-fourths of a mil. Such discrepancies as occur are doubtless due, in considerable part, to the variation in thickness from spot to spot on the specimen, for which no allowance was made in estimating the thickness from the applied weight of enamel. For specimens having the acid-resistant coating sprayed on before the under coat was fired, the line of demarcation between the two was more irregular, as might have been expected. Also, with this type of application, the tendency was for the determined thickness to be slightly greater than the estimated thickness, but the limits of error were no larger than indicated by table 1 .

TABLE 1.-Comparison of estimated and determined thickness of enamel on 6 specimens

\begin{tabular}{|c|c|c|c|c|}
\hline \multirow{2}{*}{ Specimen } & \multirow{2}{*}{ Prefired under coat } & \multicolumn{2}{|c|}{$\begin{array}{l}\text { Thickness of } A R \\
\text { coating }\end{array}$} & \multirow{2}{*}{$\begin{array}{l}\text { Difference } \\
(E-D)\end{array}$} \\
\hline & & $\underset{(E)}{\text { Estimated }}$ & $\begin{array}{c}\text { Determin- } \\
\text { ed }(D)\end{array}$ & \\
\hline $\begin{array}{l}1 \\
2 \\
3\end{array}$ & $\begin{array}{l}\text { Yes_- } \\
\text { Yes_- } \\
\text { Yes_- } \\
\text { Yes_- } \\
\text { Yes... } \\
\text { No }\end{array}$ & \begin{tabular}{r|} 
Mils \\
7.6 \\
5.5 \\
4.6 \\
4.8 \\
2.9 \\
2.6
\end{tabular} & $\begin{array}{r}\text { Mils } \\
6.8 \\
5.3 \\
4.9 \\
4.3 \\
2.9 \\
3.2\end{array}$ & $\begin{array}{l}\text { Mils } \\
+0.8 \\
+.2 \\
-.3 \\
+.5 \\
0 \\
-.6\end{array}$ \\
\hline
\end{tabular}

\section{CONCLUSION}

The method described appears to be suitable for use in specifications. It should also prove useful to manufacturers in studying the distribution of the acid-resistant layer of enamel over their products. The data gained in this way could profitably replace the assumption that the average weight per unit area applied to a commercial shape is indicative of the thickness of acid-resistant enamel on each part of the fixture, whether vertical or horizontal. The method is equally applicable to wet-process and dry-process enamels.

Washington, May 7, 1940. 